\title{
Assessing the Problem-Solving Strategies of Linear Function Using Blended Learning: The Effectiveness of Educational Social Network
}

\author{
Valdneide Almeida ${ }^{1}$, Alex Sandro Gomes ${ }^{1}$, Alina Spinilo ${ }^{2}$, Juliana Saraiva $^{3}$ \\ ${ }^{1}$ Informatics Center - Federal University of Pernambuco (UFPE) \\ Recife, Brazil \\ ${ }^{2}$ Department of Cognitive Psychology - Federal University of Pernambuco (UFPE) \\ Recife, Brazil \\ ${ }^{3}$ Exact Sciences Department - Federal University of Paraiba (UFPB) \\ Rio Tinto, Brazil \\ \{vps2, asg, alinaspinillo\}@cin.ufpe.br, julianajags@dce.ufpb.br
}

\begin{abstract}
Learning processes of Mathematics have been facing historical difficulties when the study object is an abstract issue such as Linear Function $(L F)$. In this context, mixture approach for teaching has been adopted: Blended Learning (BL). Thus, the goal of this study is to assess problemsolving strategies concerning LF when a BL approach is applied. The methodological steps were composed by face-to-face observations, virtual observations, and questionnaire application. The research was conducted at a public school with 02 teachers and 84 students. As result, 08 learning strategies were identified, and it was possible to observe evidences of the effectiveness of the BL when it was adopted in the described context.
\end{abstract}

\section{Introduction}

Although technological advances in Education, it is still appropriate to invest efforts for developing teaching materials that address the use of Information and Communication Technologies (ICT). In particular, we highlight the learning of mathematical concepts by a constructivist model of Piaget base [Vergnaud 2004]. This model aims to optimize the routine aspects of traditional classroom, as defined by Chagas (2004) [Chagas 2004]. Furthermore, it is important to note that, according to the studies of Durval (2006), function is a difficult concept to understand, however, teaching and the learning process is important because it enables the student to know the algebraic language [Durval 2006]. This type of science language is necessary to express the relationship between quantities and model problem-situations. Consequently, the comprehension of these concepts allows the students connect the concepts related to mathematics [Kieran 2006] [Saraiva 2010] [Fuente and Armentero 2011].

In this scenario, empirical studies have been performed to research educational social platforms for teaching Mathematics [Hurme and Järvelä 2005] Ding 2009 [Lazakidou and Retalis 2010]. Therefore, there are many works showing that the using of educational social platforms provide evidence for promotion, facilitation and clarification of problem-solving [Gadanidis and Namukasa 2007]. Nevertheless, an 
approach has been adopted in teaching-learning process: the Blended Learning (BL). $\mathrm{BL}$ is a term used to describe the combination of face-to-face classes with digital resources [Livingston and Condie 2007] [Macdonald 2006] [Yam and Rossini 2011] [Meejaleurn and Uratchanoprakorn 2012] [Neals 2012] [Esteves 2012] [Hein 2014] [Bernard 2014].

The purpose of this research is to analyze the effectiveness of the adoption of BL to help students during the problem-solving of Linear Function (LF). In our study, Java applets were added in the REDU (Educational Social Network) as Learning Objects (LO). The assessment of learning strategies was demanded in order to evaluate the effectiveness of the adoption of the BL. Learning strategies are techniques or methods used during the study of a specific content and/or curricular component [Boruchovitch 1999]. Therefore, the research problem is the lack of evidence about the effectiveness of the adoption of BL approach in teaching-learning process of problem-solving of LF.

Based on the problem aforementioned, research questions were formulated: (i) What are the strategies used by students to solve problems involving the concept of LF? (ii) What is the impact of the adoption of Blended Learning (BL) in the building of strategies of problem-solving involving concept of LF? The paper is organized as following: Section 2 presents the research steps. Section 3 discusses the results, and finally, the final remarks are described in Section 4.

\section{Research Methodology}

\subsection{Research Characterization}

This research is characterized as descriptive and qualitative, i.e., a method that provides an opportunity for the researcher to do analysis and interpretation of data with greater emphasis on the complexity of human behavior, describing the investigations, habits, attitudes, customs, and procedures [Marconi and Lakatos 2009]. According to Bogdan and Biklen (1994), the main focus of this type of research is given to the process, not just results [Bogdan and Biklen 1994]. The study was conducted in a public high school - Brazil, considering two learning environments: Face-to-face class and through a Educational Social Network (REDU).

- Face-to-face Classes: There were two classrooms of Mathematics where there were 43 students and 41 in the other. The research included 200 hours/class of intervention. It is important to highlight that the subject "linear function" is a part of the curriculum, corresponding 400 hours of education, composed by lectures and problem solving.

- REDU: The REDU is an Educational Social Network, for promoting new ways of collaboration and communication in education [Gomes and Rolim 2012]. The proposal REDU is to enable the creation of educational communities with different levels of access. It can enhance the interaction among participants and mutual help to create a favorable learning environment. For our study, the REDU while pedagogical research environment, contained at the LOs: "Function Machine", "Family Functions", and "Find Function". 
V Congresso Brasileiro de Informática na Educação (CBIE 2016)

Anais do XXII Workshop de Informática na Escola (WIE 2016)

\subsection{Participants (Subjects)}

The study subjects were 84 students of the first year of public high school (Brazil), and two mathematics teachers. The students had ages ranging between 15 and 17 years. The math teachers had 12 and 18 years of teaching experience, male, with 36 and 46 years old.

\subsection{Material}

Java applets were adopted and added in the REDU. They are interactive applications developed in Java programming language, and can be included in HTML code (HyperText Markup Language). These applets, included within the REDU, were our Learning Objects (LO) addressing the concept of LF. In REDU were implemented the following OA: "Function Machine", "Families Function", and "Find Function". Teachers formulated a question to be answered using each LO in order to introduce students to the task to be performed in REDU.

Students were encouraged by the teacher to use the REDU forum to discuss, and make questions about the class subject. The forum allowed them to expose how they solved the problem, ask questions to the teacher, and also to collaborate with other classmates. It is important to highlight that the classroom observations were made during the teacher's lessons in the school computer lab. Subsequently, the messages exchanged through the forum records were transcribed and analyzed qualitatively. Additionally, a questionnaire was applied. This method was applied because of the low amount of interactions recorded in the REDU forum.

\subsection{Data Assessment}

This section describes the data transcription and analysis. The transcription was composed by three steps, which are presented below:

1. Transcription of Observation Notes and "Pencil and Paper" Exercises - In this stage were transcribed the notes taken during classroom observations in order to try to capture the strategies used by students to solve FA problem.

2. Extraction and Transcription of the REDU Forum Messages - In this stage we accessed the REDU database and we have got messages posted by teachers and students. A file was saved for future analysis.

3. Transcription of Questionnaire's Answers - As the students answered the questionnaire on paper, the last step of data extraction was the transcription of students' answers to a digital file. After this, this file was also used as a source of information to be computed in $\mathrm{NVivo}^{10}$ tool. This tool was used to support us in qualitative evaluations.

The data assessment was performed using NVivo $^{10}$ tool. It is a software for evaluating textual and audiovisual data. In addition, the tool assesses dialogs, literary works, magazine articles and novels, among others.

\footnotetext{
${ }^{1} \mathrm{http}: / / \mathrm{www}$.joaonarciso.com/aplicacoes/maq_funcoes.html

2 http://www.fi.uu.nl/toepassingen/00167/toepassing_wisweb.en.html

${ }^{3}$ http://www.fi.uu.nl/toepassingen/02023/toepassing_wisweb.en.html
} 
V Congresso Brasileiro de Informática na Educação (CBIE 2016)

Anais do XXII Workshop de Informática na Escola (WIE 2016)

\section{Result Discussion}

\subsection{Classroom Observations}

During the classroom observations was possible to see that the teacher presented content (theory) of LF in lecture mode. In addition, questions were solved and discussed in class. In sequence, a list of new questions was formulated for students to solve as homework. Later, the teacher made collective corrections. An example of classroom activity is exposed in Protocol 01. The answers for the questions formulated can be observed in Figures 02 and 03, respectively.

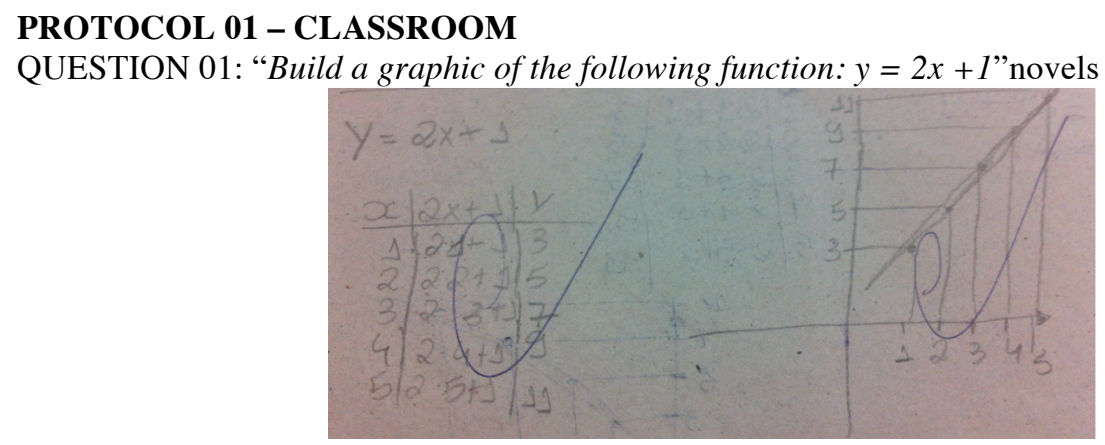

Figure 1. Example of Answer of Question 01

QUESTION 02: "Using the coordinates $(0,1)$ e $(2,5)$, compose the correspondent linear function."

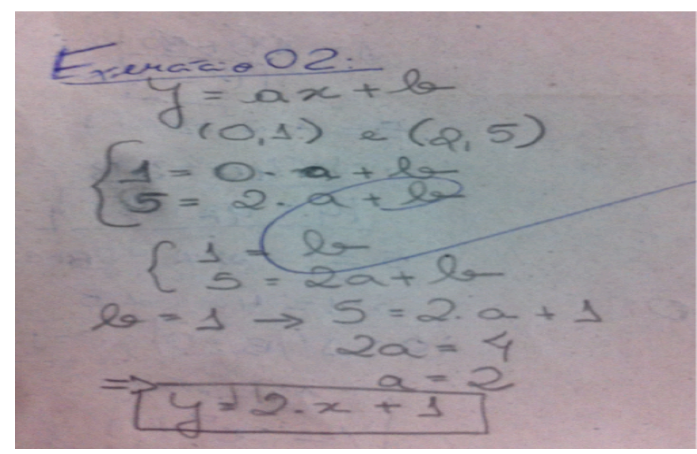

Figure 2. Example of Answer of Question 02

Figures 2 and 3 show the solutions of exercises done by a student. It illustrates the strategy used by students in the classroom. It was possible to identify the strategies used by the students to understand and solve the problems of LF. Generally, they followed the steps previously presented by the teacher.

This result is supported by the Barreto work (2009), which highlighted the importance of traditional classroom teaching in Mathematics [Barreto 2009]. The attendance of the teacher in the classroom for exposing of the subject, the proposition of exercises for the student to solve with pencil and paper, as well as the demonstration of the problem situation in the room are teaching/learning strategies necessary for understanding the concept of function. 
V Congresso Brasileiro de Informática na Educação (CBIE 2016)

Anais do XXII Workshop de Informática na Escola (WIE 2016)

\subsection{Online Observations}

This section demonstrates the activities protocols where the asynchrony collaboration was identified. We assessed the interactions between the teachers and students in the REDU forum. Protocols 2, 3 and 4 addressed this situation, while Protocol 05 depicts the questionnaire questions.

PROTOCOL 02 - REDU FORUM (2 ${ }^{\mathrm{ND}}$ ASSIGNMENT)

ASSIGNMENT 02: LO $\rightarrow$ Function Family: "Find the equation to represent the line depicted in the graphic. Choose the values of the angular coefficient $m$ and of the linear coefficient $b . "$

FORUM MESSAGE: "Teacher, I tried twice to solve this problem, but I could not do it. I do not know how to solve this problem. May you help me please?"

Considering the message aforementioned, the strategy "teacher's helping" is noted. The student tried to solve the problem and discuss about the solution in REDU forum, however, he need the teacher's assistance to get the correct answer.

FORUM MESSAGE: "I solved this problem trying sometimes different answers. I know that was logical answer."

Through the Protocol 02, it is possible to emphasize that the teacher's help has become indispensable to the student, even in the virtual environment. In this case, the student refers to the resolution of the problem based on attempt and error, which eliminating the possibilities of wrong answers.

For reason space, it is not possible to show in the paper all message and interactions exchanged between teachers and student through the REDU forum. These messages were the foundation of some learning strategies identification. On the other hand, a questionnaire was applied to extract from the students more information about the learning process. The questions that compose the questionnaire are listed below on the Protocol 03.

PROTOCOL O3 - QUESTIONNAIRE

QUESTION 01: What is your opinion about the tasks proposed by teacher using LO (applets)?

QUESTION 02: What were the difficulties found during the activities? Did you have any difficult in the assignment explanation?

QUESTION 03: Do you think that the classmates' comments helped you to performe your activities?

QUESTION 04: If you have made the first comment in the REDU forum, do you think that this comment helped other students to solve the activity asked by the teacher? If not, the other comments helped you to perform your activity?

QUESTION 05: How do you think that the "Function Machine" works? Why the x values changed the y values?

QUESTION 06: Considering the LO "Function Family" why the graphic changed when you modified the values $m$ and $b$ ? What are these values?

The application of the questionnaire allowed us to observe the learning strategies used to solve the mathematical problems through this methodological resource: LO and REDU forum. The using of technological resources enabling the manipulation and interaction with LO helped students to solve the mathematics problem, as it is possible to observe through the response of question 02 of the questionnaire "I think it was much better and was more practical using the computer with mouse".

The resolution of the mathematical problem was facilitated by the possibility of the students interact in collaboration colleagues. The evidence of this was found in the answers of questions 01,03 and 04 . The following responses were considered 
V Congresso Brasileiro de Informática na Educação (CBIE 2016)

Anais do XXII Workshop de Informática na Escola (WIE 2016)

representative: "It was cool because everybody helps everybody." "Because not only the teacher can help dispel doubts, but also our colleagues when they get home."

On the other hand, some students still prefer the face-to-face classes. It can be observed through the students responses of questions 1 and 2: "I prefer the teacher explanation because he talks in detail" and "the graphic contained in the LO helped me to find the function $f(x)=3 x+2$. I was also doing the activity in my notebook until I find the final answer". Consequently, it is notary the importance of pencil and paper for learning mathematics.

\subsection{Blended Learning Assessment}

The strategies were classified in 2 categories: Classroom (CL) and Asynchronous Collaboration (AC). Note that this categorization has been proposed in order to organize the pros and cons of each teaching-learning approach that compose the BL mode. Thus, it was possible to have an overview of the actual effectiveness of adopting BL in the context of research previously presented.

Table 1. Variables

\begin{tabular}{|c|c|c|}
\hline Strategies & Student Speech & Category \\
\hline $\begin{array}{l}\text { Immediate } \\
\text { Hit }\end{array}$ & $\begin{array}{l}\text { "The process performed by the machine can be seen as following: to have } \\
\text { the value of y terms we must multiply the value of } x \text { by } 2 \text { and then, add one." }\end{array}$ & CL/AC \\
\hline $\begin{array}{l}\text { Teacher's } \\
\text { Attendance }\end{array}$ & $\begin{array}{l}\text { “... I prefer the teacher explaining why he talks to me and explains in detail } \\
\text { the subject ..." }\end{array}$ & CL \\
\hline $\begin{array}{l}\text { Pencil and } \\
\text { Paper }\end{array}$ & "... I was doing in my notebook until obtain the final answer!" & $\mathrm{CL}$ \\
\hline $\begin{array}{l}\text { Teachers' } \\
\text { Helping }\end{array}$ & "Teacher, I did not understand how to solve this problem. May you help me? & $\mathrm{CL} / \mathrm{AC}$ \\
\hline Enumerative & $\begin{array}{l}\text { "I was putting a number } 2, \text { then another } 3 \text { and then, the machine calculated } \\
\text { until get the right result." }\end{array}$ & $\mathrm{AC}$ \\
\hline Using of LO & "I did it! Very practical using the mouse." & $\mathrm{AC}$ \\
\hline $\begin{array}{l}\text { Reverse } \\
\text { Reasoning }\end{array}$ & $\begin{array}{l}\text { "With graphic I could find the response of the first function of }(x)=3 x+2 . \\
\text { After that, I was doing looking at the tip of the graphic and I answered } \\
\text { linking the line points." }\end{array}$ & $\mathrm{AC}$ \\
\hline Social & $\begin{array}{l}\text { "I looked at the colleagues' response and I could better understand the } \\
\text { formula." }\end{array}$ & $\mathrm{AC}$ \\
\hline
\end{tabular}

After categorization, the strategies were associated with each category identified. These were defined based on related studies regarding learning strategies, and also based on theories related to the teaching-learning process. All strategies are described as following. In addition, Table I shows them, where the first column indicates the name of the strategy, while the second column shows an example of the student speech that was used to identify the strategy. Finally, the third column indicates the strategy's category: (i) Immediate Hit: The student, after reading the statement, hits the activity immediately, without explaining the learning process [Barreto 2009]; (ii) Teacher's Attendance: In this scenario, the student needs to talk to the teacher in person. Essentially the interaction between student and teacher is immediate [Chagas 2004] [Vygotsky 2007]; (iii) Pencil and Paper: In this strategy, the student resolves math problem sketching on paper the reasoning logically [Chagas 2004] [Barreto 2009]; 
(iv) Teacher's Help: In this scenario, the teacher's helping is needed. However, it is important to clarify that this help can be online or in person [Dillenbourg and Traum 2006]; (v) Enumerative: This strategy involves the reasoning based on the elimination, or on attempt and error [Echeverría and Pozo 1998] [Vergnaud 2004]; (vi) Using of LO: In this scenario, the student needs to manipulate and interact with the LO to solve the problem. It is the transition from the abstract to the concrete [36]; (vii) Inverse Reasoning: It is found when the student by observing the generated graphic, finds the requested function in the question [Barreto 2009]; (viii) Social: This is happened when the students solved the math problem interacting with others Ding 2009 [Vygotsky 2007].

\subsection{Answering Research Questions}

This section presents the responses of the listed research questions previously presented. Below are the answers given to the following questions:

QUESTION 01: What are the strategies used by students to solve problems involving the concept of LF? (i) Immediate Hit, (ii) Teachers' Attendance, (iii) Pencil and Paper, (iv) Teachers' Helping, (v) Enumerative, (vi) Using of LO, (vii) Reverse Reasoning, and (viii) Social. The strategies were classified into 2 categories: (i) Classroom (ii) Asynchronous Collaboration. They were identified from the dialogues of students in the REDU forum, and also based on their questionnaire responses.

QUESTION 02: What is the impact of the adoption of Blended Learning (BL) in the building of strategies of problem-solving involving concept of LF? With the results presented and discussed in the previous section, it is possible to note that the face-toface classroom combined with the online approach, presents a more effective model in teaching process for high school students when they are learning problem-solving of LF. It was possible to infer that with the adoption of BL, teachers can make easier the understanding of an abstract concept, such as is the definition of LF. This conclusion was observed through the analysis of forum posts where students indicated that it was easier to understand the LF subject interacting with the LOs. As characteristic of the forum itself, doubts and consequent answers were persisted. Thus, students who could not attend the face-to-face class can access this information any time. This situation provides the independence of space-time, in which limits the teaching-learning process when it occurs in a strictly face-to-face mode.

Additionally, there is the wide deployment of knowledge construction process. It means that there is construction of knowledge involving several people in different modes of learning. Another important issue to point out is the increasing of collaboration between students for the dissemination of knowledge between them. Thus, the virtual environments provide to the students answer the questions talking to themselves. This behavior is not common in the classroom mode, but in our study the students reported us that other students answered questions that would normally be directed to teachers were answered by them.

Therefore, discussing the impact of the adoption of BL to teach LF in high school, we can demonstrate the advantages and drawbacks of its using. It is important to highlight that similar studies were performed to assess BL approach, however, our research checked the effectiveness of it to teach an specific subject: linear function. 
V Congresso Brasileiro de Informática na Educação (CBIE 2016)

Anais do XXII Workshop de Informática na Escola (WIE 2016)

\section{Concluding Remarks}

It was possible to observe that challenges are found in the teaching-learning process of the Linear Function (LF) concepts in High School level. Therefore, a mix learning approach, called Blended Learning (BL) was assessed in the context of problem-solving of LF. A study was conducted in a public school in Brazil, with 15 and 17 years old students, and their Mathematics teachers. The students were in the $1^{\text {st }}$ year of High School. Classroom and online observations were performed, and a questionnaire was also applied. It is important to highlight that the REDU (Social Educational Network) was adopted as online environment and 3 applets related to LF were installed there.The data assessment was done using the NVivo tool that aims the researchers in qualitative evaluations. It is important to mention that all the research steps were presented here. Consequently, it is possible to replicate our study to confirm or refute the results discussed. It was possible to identify 08 strategies used to solve problems related to LF: (i) Immediate Hit, (ii) Teacher's Attendance, (iii) Pencil and paper, (iv) Teacher's Helping, (v) Enumerative, (vi) Using of LO, (vii) Inverse Reasoning, and (viii) Social. Additionally, 02 categories were proposed to classify the strategies: (i) Classroom, and (ii) Acronym Collaboration. The strategies identification helped us for understanding of the student learning process because their steps for reasoning building were exposed.

Nevertheless, the study has some threats. The first one was about the school that has a poor infrastructure for information technology. Thus, sometimes, the teacher was feeling discouraged for preparing classes that involving computer activities. In addition, the Internet was interrupted during the activities performance. Other important issue to be noted is that because the large amount of tasks to do, the teachers have not interacted with the students in the forum. Therefore, the students haven't received feedbacks about the activities every day, and the number of interaction decreased in REDU forum. Another research limitation was the low number of teachers who joined the BL approach. Out of 20 school's teachers that participated of the REDU training, and only 2 have proposed to participate and join. It can be occurred because the teachers have many activities as teacher and they did not want one more task to be done.

Regarding to REDU network, it was observed that teachers and students needed to insert mathematical symbols and then, they failed. This hampered the communication and interaction in some activities. Another point that should be considered as a limitation is that the inclusion of comments in the forum did not provide a friendly interaction for users. This means that, when they click the "Comment" button, the LOs and the other reviews could not be viewed directly. The user should rotate the scroll bar to see what had already been said at the end of the webpage. Finally, when analyzing the limitations of this study, it is important to remember that while 08 strategies have been identified, our studies need to be redone analyze the results found. In addition, the categories of strategies have been proposed from a qualitative assessment of the data. Consequently, there may have been a misinterpretation of information and new strategies can be identified, as well as new categories may be proposed in future work. And more, it is important to remember that while 08 strategies have been identified, our studies need replicate our research to analyze the results found here.

This study provided evidences regarding the effectiveness of BL approach. We found some gaps that can be seen as future work. During the observations, and the period of training of teachers in REDU, we observed that teachers needed insert 
V Congresso Brasileiro de Informática na Educação (CBIE 2016)

Anais do XXII Workshop de Informática na Escola (WIE 2016)

formulas and some mathematical symbols in the comments, when they were interacting with students in the REDU forum. Thus, the inclusion of a mathematical editor in REDU is demanded. It is clear the importance of mixed teaching-learning approach applied to LF in high school. The using of classroom activities combined with the technological resources in collaborative environments indicated good way to teach mathematics.

\section{References}

Vergnaud, G. (1997) "The nature of mathematical concepts", In: NUNES, T.; BRYANT, P. (Ed.). Learning and teaching mathematics: An international Perspective. Hove: Psychology Press, p. 5-28.

Chagas, E. M. (2004) "Educação Matemática na Sala de Aula: Problemáticas e Possíveis Soluções”.

Durval, R. (2006) "Quelle semiotique pour l'analyse de la activité et dês productions mathématiques?" (in French), In: Revista Latinoamericana de Investigacion en Matemática Educative, 9 (1), p. 45-82.

Kieran, C. (2006) "Research on the learning and teaching of algebra: A broadening of sources of meaning", In: GUTIÉRREZ, A.; BOERO, P. (Ed.). Handboook of research on the psychology of mathematics education. Otterdam: Sense, p. 11-50.

Saraiva, M. J. and Teixeira, A. M. and Andrade, J. M. (2010) "Estudos de funções no programa de matemática com problemas e tarefas de exploração" (in Portuguese). Lisboa.

Fuente, A. and Armenteros, M. (2011) "Significados pretendidos y personales en un proceso de estudio con el límite functional" (in Spanish)., In: Revista Latinoamericana de Investigación en Matemática Educativa, 14 (3), p. 277-310.

Hurme, T-R. and Järvelä, S. (2005) "Students' activity in computer supported collaborative problem solving in mathematics", In: International Journal of Computers for Mathematical Learning, 10, p. 49-73.

Ding, N. (2009) "Visualizing the sequential process of knowledge elaboration in computer-supported collaborative problem solving", In: Computers \& Education Journal, v. 52, n. 2, p. 509-519.

Lazakidou, G. and Retalis, S. (2010) "Using computer supported collaborative learning strategies for helping students acquire self-regulated problem solving skills in Mathematics", In: Computers \& Education Journal, 54(1), p. 3-13.

Gadanidis, G. and Namukasa, I. (2007) "Mathematics-for-teachers (and students)", In: Journal of Teaching and Learning, 5(1), p. 13-22.

Livingston, K. and Condie, R. (2007) "Blending online learning with traditional approaches: changing practices", In: British Journal of Educational Technology, p. 337-348.

Macdonald, J. (2006) "Blended Learning and Online Tutoring: A Good Practice Guide" Aldershot, UK: Gower. 
V Congresso Brasileiro de Informática na Educação (CBIE 2016)

Anais do XXII Workshop de Informática na Escola (WIE 2016)

Meejaleurn, S. and Uratchanoprakorn, A. and Boonlue, S. (2012) "The Construction of the online-learning in a group activity using blended learning on the information communication and network system at Grade 9"In: Proceedings of Computer Technology and Development (ICCTD). NY: ICCTD. p. 389-392.

Boruchovitch, E. (1999) "Estratégias de aprendizagem e desempenho escolar: considerações para a prática educacional", In: Jornal de Psicologia: Reflexão e Crítica, 12 (2), p. 1-17.

Kay, R. (2012) "Examining Factors That Influence the Effectiveness of Learning Objects. Mathematics Classrooms", In: Canadian Journal of Science, Mathematics and Technology Education , 12 (4), p. 350-366.

Dillenbourg, P. and Traum, D. (2006 ) "Sharing solutions: persistence and grounding in multi-modal collaborative problem solving", In: Journal of the Learning Sciences, 15 (1), p. 121-151.

Schreurs, J. and Al-Huneidi, A. (2012) "Constructivism based blended learning in higher education", In: International Journal of Emerging Technologies in Learning (iJET), 7 (1), p. 4-9.

Hein, J. O. 2014 "A comparison of a blended learning environment and a traditional learning environment are student achievement and student interest affected?".

Marconi, M. and Lakatos, E. (2009) "Fundamentos de metodologia científica" (in Portuguese). 6. ed. São Paulo: Atlas, São Paulo.

Bogdan, R. and Biklen, S. K. (1994) "Investigação Qualitativa em educação: uma introdução à teoria e aos métodos" (in Portuguese). Porto, Portugal: Editora Porto.

Gomes, A. and Rolim, A. and Silva, W. (2012) "Educar com o REDU" (In Portuguese). Recife.

Barreto, A. L. (2009) "Análise da Compreensão do conceito de função mediado por ambientes computacionais", Thesis (in Portuguese) - UFC, Fortaleza.

Vygotsky, L. S. (2007) “A formação social da mente”, São Paulo: Martins Fontes.

Echeverría, M. P. P. and pozo, J. I. (1998) “Aprender a resolver problemas e resolver problemas para aprender" (in Portuguese).

Neals (2012) "Ultranet and Digital Learning Branch. Department of Education and Early Childhood Development Melbourne", March.

Esteves, C. M. A. (2012) "O b-learning como modalidade válida de aprendizagem no 1. Ciclo do Ensino Básico: Estudo de caso com uma turma do $3 .^{\circ}$ ano de escolaridade", Dissertation (in Portuguese).

Hein, J. O. (2014) "A comparison of a blended learning environment and a traditional learning environment are student achievement and student interest affected?".

Bernard, R. M. et al. (2014) "A meta-analysis of blended learning and technology use in higher education: from the general to the applied", In: Journal of Computing in Higher Education, 26 (1), p. 87-122.

Yam, S. and Rossini, P. (2011), "Online learning and blended learning: which is more effective?", In: 17th Annual Conference, 16-19, Gold Coast. 